\title{
Prevalence of vertical HIV infection and its risk factors among HIV exposed infants in East Africa: a systematic review and meta- analysis
}

Amare Belachew $^{1 *}$ (D) Tilahun Tewabe ${ }^{1}$ and Gizat Abinet Malede ${ }^{2}$

\begin{abstract}
Background: Human immunodeficiency virus (HIV) is one of the most important global health problems. More than one and half million of children are living with HIV in the world, and majority of them are found in subSaharan Africa. There are primary fragmented study findings, and no review was conducted with regard to vertical HIV infection in East Africa. Therefore, this review aimed to assess the prevalence of vertical HIV infection and its risk factors among HIV-exposed infants in East Africa.

Main body: Eligible studies were retrieved by relevant search terms in CINHAL, Pub-MED, Google Scholar, EMBASE, Web of Science, SCOPUS, Cochrane, African Journals Online databases, and Ethiopian University research repositories. Data were extracted with Microsoft Excel and analyzed with Stata version 11 software. The random effect model was used to estimate the pooled prevalence of vertical HIV infection in East Africa. The variation between studies was quantified with an $P^{2}$ statistic test. Furthermore, sub-group and meta-regression analyses were done to identify the sources of heterogeneity between the studies. The publication bias was assessed by Egger test. This systematic review and meta-analysis have included a total of 33 research articles. The overall pooled prevalence of vertical HIV infection in East Africa was $7.68 \%$ with a $95 \%$ confidence interval $[C I]:(6.23,9.12)$ with a heterogeneity of $P^{2}=86.8$ with a $p$ value $<0.001$. In subgroup analysis, the pooled prevalence of vertical HIV infection in cross-sectional studies was 6.58\%, while in cohort studies were 9.37\%. Mixed feeding, AOR $=6.22(1.02$, 11.41); home delivery, $\mathrm{AOR}=2(1.01,3)$; mothers took ART less than 4 weeks, $A O R=1.92(1.79,2.06)$; and infants who have not received ARV prophylaxis, $A O R=2.02(1.05,2.98)$ were the associated factors for vertical HIV infection for exposed infants.
\end{abstract}

Conclusions: The pooled prevalence of the mother to child transmission of HIV is way more than the desired target of the World Health Organization, which is less than 5\% in breastfeeding populations. Thus, strengthening the prevention of vertical HIV transmission, promotion of exclusive breastfeeding, timely initiation of ART prophylaxis for HIV exposed infants, encouragement of hospital delivery, and the start of ART at the time of diagnosis of every HIV-positive person may all reduce the transmission of vertical HIV infection.

Keywords: HIV, Incidence, MTCT, PMTCT, Prevalence, Burden, Risk, Vertical HIV infection, Rate of vertical HIV infection, HIV-exposed infant, East Africa

\footnotetext{
* Correspondence: belamare8@gmail.com

${ }^{1}$ Department of Pediatrics and Child Health Nursing, College of Medicine

and Health Sciences, Bahir Dar University, Bahir Dar, Ethiopia

Full list of author information is available at the end of the article
}

(c) The Author(s). 2020 Open Access This article is licensed under a Creative Commons Attribution 4.0 International License, which permits use, sharing, adaptation, distribution and reproduction in any medium or format, as long as you give appropriate credit to the original author(s) and the source, provide a link to the Creative Commons licence, and indicate if changes were made. The images or other third party material in this article are included in the article's Creative Commons licence, unless indicated otherwise in a credit line to the material. If material is not included in the article's Creative Commons licence and your intended use is not permitted by statutory regulation or exceeds the permitted use, you will need to obtain permission directly from the copyright holder. To view a copy of this licence, visit http://creativecommons.org/licenses/by/4.0/. 


\section{Background}

Human immunodeficiency virus (HIV) affects our immune system that helps to defend infections and illnesses in our body system [1]. About 37.9 million people are the carrier of HIV in the globe. Of this, 1.7 million are children and most of them are found in sub-Saharan Africa [1].

The youngsters were acquired HIV during pregnancy, childbirth, and breastfeeding $[1,2]$. The chance of vertical HIV infection without any intervention during pregnancy and delivery reach to $15-30 \%$ [2], breastfeeding, 5-20\% [3], and overall transmission reach to $15-45 \%$ [3, 4]. Providing timely antiretroviral prophylaxis for HIV-exposed infants and ART for HIV-positive mothers are helping to cut back the risk below $5 \%[3,4]$.

Different strategies were recommended and implemented by WHO to prevent vertical HIV infection in different countries such as increasing antenatal care visits, promoting institutional delivery, strengthening prevention of vertical HIV transmission services, and ART services $[1,3,4]$. But the problem is still prevalent in sub-Saharan Africa countries [1].

Different studies were conducted to assess the magnitude of vertical HIV infection, and its association with mixed feeding, place of delivery, timely initiation of ART prophylaxis among HIV-exposed infants, and duration and initiation of antiretroviral therapy (ART) for HIVinfected mothers in East Africa [5-37]. But the reports of these research findings brought with great differences within the magnitude of vertical HIV infection across the countries' geographical regions.

The place of delivery $[6,7,10,14,18,21,24,25,27$, $38,39]$, mixed feeding $[6,9,15,21,25,27,39]$, mother's age $[5,24]$, residence $[7,27]$, time to initiate infant prophylaxis [7-10, 27], mother's HIV stage [9, 18], antenatal care visits $[8,9,18]$, prevention of vertical HIV infection [6, 7, 24], and feeding practices [7, 8, 24] were a number of the factors for acquisitions of HIV infection for exposed infants and children. Of these factors, four factors (place of delivery, duration of mother on ART, initiation of ART prophylaxis for newborns, and mixed feeding) were chosen to work out their effect on vertical HIV infection. Within the bulk of studies, the chosen factors were predictors of vertical HIV infection, while in some studies, they showed a negative association. This disagreement is not well investigated. Thus, the purpose of this review aimed to estimate the pooled prevalence of vertical HIV transmission and its associated factors among HIV-exposed infants in the geographical regions. This study finding may help an input for program planners, used to monitor the progress of PMTCT programs, policymakers, and further research.

\section{Methods}

This systematic review and meta-analysis followed the guideline of Preferred Reporting Item for Systematic Reviews and Meta-analysis [40]. The protocol of the development of this systematic review and meta-analysis is under process on PROSPERO databases with ID of 147647.

\section{Search strategy and study design}

Eligible published studies were searched in CINHAL, Pub-MED, Google Scholar, EMBASE, Web of Science, SCOPUS, Cochrane, African Journals Online databases, and Ethiopian University research repositories. The searching terms were "prevalence"; "burden"; " proportion"; "incidence"; "factors"; "barriers"; "predictors"; "vertical HIV infection", "HIV exposed infants", "mother to child"; "mother to baby"; "mother"; "infant", 'MTCT'; " Mother to child transmission of HIV", "HIV"; "human immunodeficiency virus"; "AIDS"; "Acquired immunodeficiency syndrome"; and "East Africa or each specific countries (Ethiopia, Kenya, Tanzania, Djibouti, Eritrea, Uganda, Somali, South Sudan, Rwanda, Zimbabwe, Mozambique, Malawi, and Burundi )". Boolean operator terms were searched separately and together accordingly as "OR" or "AND" or AND NOT or AND, NOT. Gray literature from the research online library repository and manual search of references were also searched.

\section{Eligibility criteria}

Studies were included if: (1) studies conducted in East Africa; (2) all studies were done regarding the prevalence of vertical HIV infection or its association with mixed feeding, place of delivery, time of prophylaxis begun, and length of starting ART drug among HIVexposed infants in East Africa; (3) papers published only in the English language. Studies were excluded in this meta-analysis when: (1) the study is qualitative, (2) was published in a book, (3) research reports that were not accessed and not written in English were excluded because of difficulty in assessing the quality of each article.

\section{Measuring outcome variables}

This review has two outcome variables. The first outcome of this review was the magnitude of vertical HIV infection among HIV-exposed infants. The HIVpositive infant was confirmed at 6 weeks or after using deoxyribonucleic acid-polymerase chain reaction (DNA-PCR) virology tests or 18 months or above using the DNA-PCR test or rapid antibody test after 6 weeks of breastfeeding cessation [4]. The duration of the study ranges from birth to 24 months old. The second outcome was to look at the association 
between mixed feeding, duration of mother on ART, infant ART prophylaxis at birth, place of birth, and vertical HIV infection. In this study, mixed feeding implies that HIV-positive mothers feed their newborn infant both breast milk and other food or fluid within 6 months of birth. The adjusted odds ratio was undertaken between mixed feeding, initiation of ART prophylaxis, duration of mother on ART, place of birth, and vertical HIV infection of infants.

\section{Quality assessment}

Each research article was critically appraised by using the Joanna Briggs Institute Meta-Analysis of Statistics Assessment and Review Instrument (JBI-MAStARI) [41]. The criteria include both the inclusion and clear definition criteria of the inclusion of sample, selection of the study participants, confounding factors, outcome of interest, and consistent measurement of outcome variable and statistical analysis methods [41]. Reviewers were dealing it before the extraction of the data. Two independent reviewers carried out the searches to extract the data. Data extraction was carried out by the Joanna Briggs Institute (JBI) tool for prevalence studies [41]. It includes a primary author, year of the publication, study area, sample size, study design, region of the study, prevalence of vertical HIV infection, time of infant HIV diagnosis, and a total number of HIV-positive and HIVnegative infants by breastfeeding option, infant ARV prophylaxis, place of delivery, and mother's PMTCT intervention status. Reviewers independently carried out article inclusion, data extraction, and compared results. Finally, the disagreements were resolved by a consensus between the two reviewers.

\section{Statistical methods and analysis}

STATA version 11 software was used to analysis of the data. The pooled magnitude of mother to child transmission of HIV was estimated with DerSimonian and Laird's random-effects model. Furthermore, subgroup and univariate meta-regression analyses were undertaken with sample size, study setting, study design, country, and publication date. The adjusted odds ratio was used to predict between vertical HIV infection with mixed feeding, place of delivery, duration of mother on ART, and infant received ART prophylaxis at birth.

\section{Heterogeneity and publication bias}

The $I^{2}$ statistic test was used to quantify heterogeneity between the studies and a $p$ value less than 0.05 declared as statically significant [42]. The Duval and Tweedie nonparametric trim and fill analysis followed by Egger test were conducted for assessing publication bias (Egger test, $p<0.05)[41-43]$.

\section{Results}

A total of 867 articles were retrieved regarding vertical HIV infection in East Africa. Of this, 415 were searched from PubMed, 225 articles from Google Scholar, 90 articles from ScienceDirect, and 137 from others. From total extracted articles, 798 were expelled because of duplications and irrelevancies, and 32 were removed after abstract and title screening. But thirty-seven studies met the eligibility criteria, and four articles were removed because they did not report the outcome interest [44-47]. Finally, 33 studies were included in this meta-analysis (Fig. 1).

\section{Characteristics of the included studies}

A total of 33 published articles were included in this study. In this review, a total of 428124 of HIV exposed infants were involved to calculate the pooled magnitude of vertical HIV infection. Articles done both on cohort and cross-sectional study designs were incorporated in this study. The peak prevalence $(32.1 \%)$ of MTCT of HIV was found from a study done in Ethiopia [28], while the lowest magnitude (1.58\%) was found in Rwanda [36]. A total of nine countries and 33 studies were included in this systematic review and meta-analysis. Of this, sixteen studies were from Ethiopia (5-11, 21-24, 26-28, 37, 38 ), five studies were from Kenya [12, 15, 20], three studies were from Tanzania $[13,16]$, three studies were from Uganda [14, 18, 19, 31], two studies were from Zimbabwe [33, 34], and the remaining one study was from Eritrea [19], South Sudan [32], Malawi [35], and Rewanda [36]. In this review, eighteen studies were cross-sectional study designs while fifteen studies were cohorts (Table 1).

\section{Publication bias}

Publication bias was assessed by Egger test. The result of Egger test was statistically significant for estimating the magnitude of HIV-positive infants $(p<0.001)$. Egger test of the intercepts (B0) was $0.99((\mathrm{CI})=0.973,1.02)$. Trim fill analysis was conducted and it showed that there is a remaining study in graphs. But the confidence interval is overlapped and it is not significant (Fig. 2).

\section{Overall pooled magnitude of vertical HIV infection}

The result of thirty-three studies showed that the pooled magnitude of vertical HIV infection in Eastern Africa was $7.68 \%$ (CI 6.23, 9.12). There was a severe heterogeneity across the studies $\left(I^{2}=86.8 \%, p\right.$ value $\left.<0.001\right)$. Due to severe heterogeneity, subgroup analysis was carried out with study design (Fig. 3). The higher prevalence of vertical HIV infection was observed in Ethiopia (32.1\%), while the lower prevalence was in Rwanda (1.58\%). 


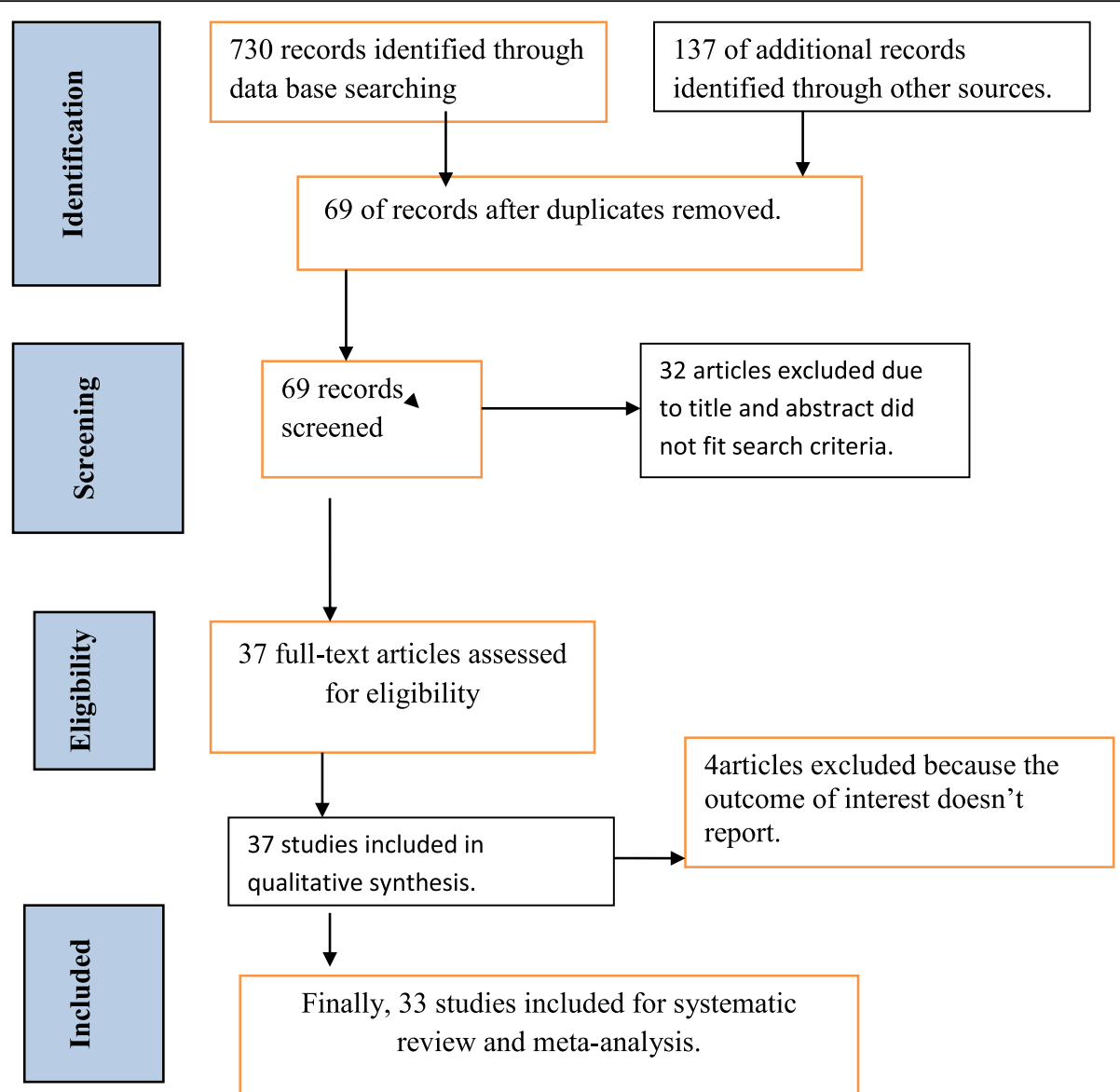

Fig. 1 Flowchart diagram of search strategy and article selection for vertical HIV infection in East Africa, 2019

\section{Meta regressions}

The univariate meta-regression model was done with publication date, sample size, country, and study design for identifying the source of heterogeneity and none of them were statically significant (Table 2).

\section{Place of delivery and vertical HIV infection}

Eleven studies were included to assess the association between place of delivery and HIV infection $[6,7,10,14$, $18,21,24,25,27,37,38]$. The findings showed that the place of delivery was significantly associated with vertical transmission of HIV. The odds ratio of infants who were delivered at home were 2 times more likely to acquire HIV infection than those who were delivered at health facilities (AOR: 2.00, 95\% CI 1.01, 3.00). No heterogeneity $(I=0.0 \%$ and $p$ value $=0.852)$ was observed across the included studies (Fig. 4).

\section{Mixed feeding and vertical HIV infection}

A total of ten studies [6, 7, 9, 10, 15, 21, 25, 27, 38] were included in this meta-analysis to show the significance between mixed feeding and MTCT of HIV. The pooled odds ratio showed that mothers practiced mixed feeding for their exposed infants were 6.22 times more likely to acquire HIV infection than exclusively breastfeeding exposed infants $(\mathrm{AOR}=6.22(1.02,11.41)$. There is a severe heterogeneity across the studies $\left(I^{2}=96.5 \%\right.$ and $p$ value $<0.001)$. Egger test was done to detect the publication bias, but there is no revealed significant on publication bias with a $p$ value of 0.074 (Fig. 4).

\section{Duration of mothers on ART and MTCT of HIV}

Five studies ( $[6,15,18,25,27])$ were included in this study to estimate the pooled effect of the duration of the mother's on ART with vertical HIV infection. The odds ratio of mothers taking ART less than 4 weeks were 1.92 times more likely to transmit HIV infection to their exposed infant as compared to those who were on ART for more than 4 weeks (AOR $=1.92(1.79,2.06)$. No heterogeneity $(I=0.0 \%$ and $p$ value $=0.744)$ was observed across the included studies (Fig. 4). 
Table 1 Descriptive summary of 33 studies included in the meta-analysis of the prevalence of vertical HIV infection in East Africa, 2019

\begin{tabular}{|c|c|c|c|c|c|}
\hline Authors/year of publication & Country & Study design & Sample size $(N)$ & Magnitude of vertical HIV infection (\%) & Quality \\
\hline Moges et al. 2017 [5] & Ethiopia & Cohort & 305 & 5.9 & Low risk \\
\hline Obsa et al. 2018 [6] & Ethiopia & Cohort & 492 & 7.7 & Low risk \\
\hline Birlie et al. 2016 [7] & Ethiopia & Cohort & 146 & 17 & Low risk \\
\hline Derbe et al. 2014 [8] & Ethiopia & Cohort & 426 & 9.6 & Low risk \\
\hline Tadele et al. 2014 [9] & Ethiopia & Cohort & 457 & 4.16 & Low risk \\
\hline Wudineh et al. 2016 [10] & Ethiopia & Cohort & 382 & 15.7 & Low risk \\
\hline Negash et al. 2016 [11] & Ethiopia & Cohort & 384 & 6 & Low risk \\
\hline Sirengo et al. 2014 [12] & Kenya & Cross-sectional & 63 & 12.7 & Low risk \\
\hline Gamell et al. 2017 [13] & Tanzania & Cohort & 135 & 2.2 & Low risk \\
\hline Kahungn et al. 2018 [14] & Uganda & Cross-sectional & 493 & 6.5 & Low risk \\
\hline Mwau et al. 2017 [15] & Kenya & Cross-sectional & 365841 & 8.9 & Low risk \\
\hline Mwando et al. 2014 [16] & Tanzania & Cross-sectional & 561 & 9.6 & Low risk \\
\hline Mirambo et al. 2014 [17] & Tanzania & Cross-sectional & 1005 & 6.1 & Low risk \\
\hline Izudi et al. 2018 [18] & Uganda & Cohort & 295 & 8.5 & Low risk \\
\hline Teclebirhan et al. 2009 [19] & Eritrea & Cohort & 105 & 4.7 & Low risk \\
\hline Khobondo et al. 2015 [20] & Kenya & Cross-sectional & 360 & 10.6 & Low risk \\
\hline Tsehay et al. 2019 [21] & Ethiopia & Cross-sectional & 27 & 5.8 & Low risk \\
\hline Desta [22] & Ethiopia & Cross-sectional & 350 & 2.1 & Low risk \\
\hline Mirkuzie et al. 2010 [23] & Ethiopia & Cross-sectional & 896 & 11.8 & Low risk \\
\hline Koye et al. 2013 [24] & Ethiopia & Cohort & 509 & 10 & Low risk \\
\hline MAMA A et al. 2015 [25] & Ethiopia & Cross-sectional & 10 & 7.7 & Low risk \\
\hline Mirkuzie et al. 2011 [26] & Ethiopia & Cohort & 71 & 8.4 & Low risk \\
\hline Berhan et al. 2014 [27] & Ethiopia & Cohort & 434 & 10.10 & Low risk \\
\hline Hassen et al. 2014 [28] & Ethiopia & Cohort & 159 & 32.1 & Low risk \\
\hline Makau et al. 2015 [29] & Kenya & Cross-sectional & 238 & 8.4 & Low risk \\
\hline Ashino et al. 2017 [30] & Kenya & Cross-sectional & 2642 & 9.27 & Low risk \\
\hline Obai et al. 2017 [31] & Uganda & Cohort & 410 & 5.8 & Low risk \\
\hline Gawar (a) et al. 2019 [32] & South Sudan & Cross-sectional & 828 & 2.8 & Low risk \\
\hline Buzdugan etal. 2015 [33] & Zimbabwe & Cross-sectional & 8568 & 8.8 & Low risk \\
\hline Ndaimani et al. 2018 [34] & Zimbabwe & Cross-sectional & 5836 & 4.4 & Low risk \\
\hline van Lettow et al. 2018 [35] & Malawi & Cross-sectional & 33744 & 4.7 & Low risk \\
\hline Mugwaneza et al. 2018 [36] & Rewanda & Cross-sectional & 1639 & 1.58 & Low risk \\
\hline Yitayew [37] & Ethiopia & Cross-sectional & 313 & 3.8 & Low risk \\
\hline
\end{tabular}

\section{Absence of infant received ART prophylaxis at birth and MTCT of HIV}

Eight studies ( $[6,9,10,15,21,25,27,38])$ included in this meta-analysis to indicate the impact of providing ART prophylaxis at birth. Infants who were not taking ART prophylaxis were 2.02 times more likely to acquire HIV infection than those who were taking ART prophylaxis $(\mathrm{AOR}=2.02(1.05,2.98)$. The heterogeneity across the study was $\left(I^{2}=3.2 \%\right.$ and $p$ value $=0.405)($ Fig. 5).

\section{Discussion}

While much effort was done to tackle the vertical transmission of HIV in East Africa, the transmission of mother to child is still prevalent. Thus, this systematic review aimed to assess the pooled prevalence of vertical HIV infection and its associated factors among HIVexposed infants in East Africa.

The overall pooled prevalence of vertical HIV infection among HIV-exposed infants in East Africa was 7.68\% (95\% CI 6.23, 9.12), and this finding is high compared to 
Filled funnel plot with pseudo $95 \%$ confidence limits

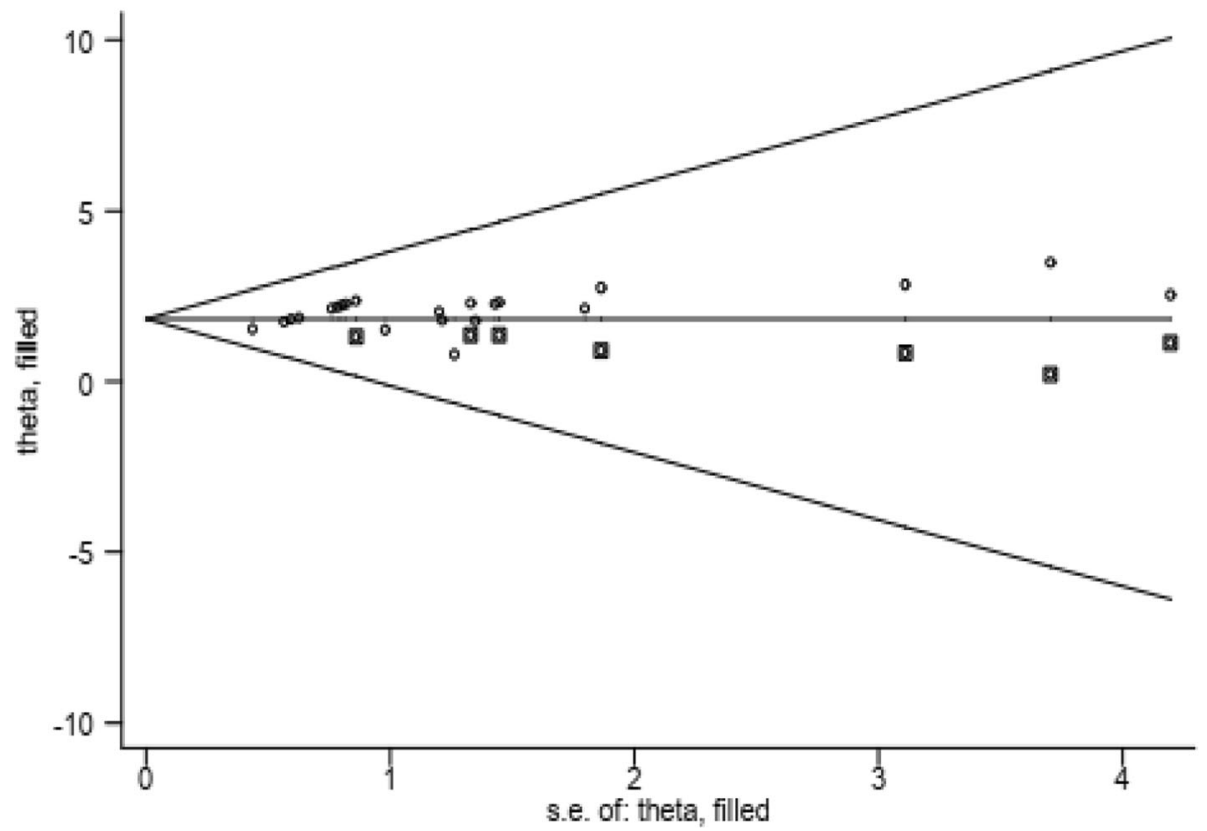

Fig. 2 Frim-trill analysis result of 33 included studies for vertical HIV infection in East Africa, 2019

WHO setting strategies of achieving zero incidences of new HIV infection among HIV-exposed infants by 2020 $[48,49]$. This finding is higher than studies done in China, 3.9\% (95\% CI 3.2, 4.6\%) [49], and Cuba and Thailand eliminated of MTCT of HIV [50,51]. The possible reason for this discrepancy may be there is deference's in socio-demographic characteristics, economic, access to ART services, and health care-seeking behavior of the respondents. Additionally, countries like Cuba and Thailand have maintained a strong commitment to the PMTCT of HIV and successfully integrated PMTCT interventions into maternal and child health services than East Africa countries [50]. Similarly, this finding also shows the high-vertical transmission of HIV compared to South Africa, the risk of MTCT at 18 months was $4.3 \%$ [52]. This discrepancy may be due to in South Africa, more than 95\% antenatal HIV testing uptake and triple ART coverage ( $\geq 93 \%$ ) compared to the current study settings and this helps in the reduction of MTCT of HIV in South Africa compared to this study [52]. Additionally, there is a literature report that there is a poor intake of PMTCT services in developing countries due to different reasons as compared to the developed ones [53].

The sub-group analysis of both cohort and crosssectional studies has a similar pooled prevalence of vertical HIV infections, which accounts for 9.37\% and 6.58\%, respectively. While they have similar pooled prevalence, there was observed high heterogeneity in cohort studies than cross-sectional ones.

Vertical HIV infection was influenced by various factors. Infants who delivered at home were 2.00 times to acquire HIV infection compared to those who delivered at health facilities. This finding is in line with studies done in Nigeria [53] and Zimbabwe [54]. This might flow from to inaccessible of PMTCT services for those who were delivered at home. Besides, mothers who gave birth at home may have a high probability to practice prelactal feeding, poorly managed cords like using unsterilized sharp materials, high chance of placenta contamination with the blood, breastfeeding of infants from the unknown status of mothers, and uvulectomy practices. These activities may expose newborns more for viral infections [55-58].

Mixed feeding is one of the most risk factors of acquiring HIV infection for exposed infants. HIV-exposed infants who fed both breast milk and other liquid or fluid within the 6 months of birth were 6.22 times more acquired HIV infection compared to exclusive breastfeeding infants. The result of this finding is consistent with the study findings in Zimbabwe [58] and South Africa [59]. This may be due to mixed feeding cause gastric mucosal ulceration and the laceration of mucus creates a favorable entry of the virus into the bloodstream $[4,60]$. 


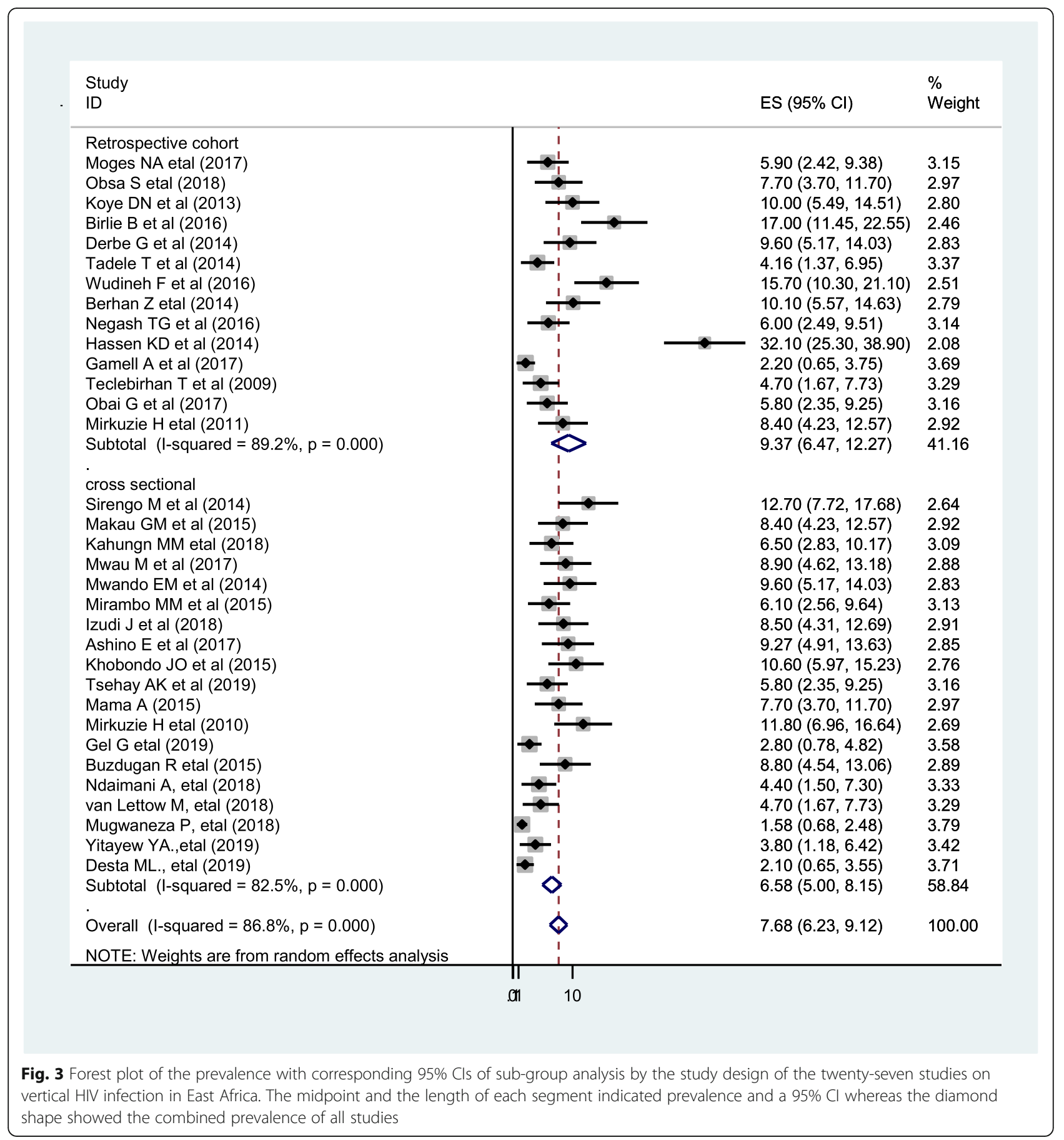

Infants who did not receive ART prophylaxis at birth were 2.02 times more likely to acquire HIV infection compared to those who were taken ART prophylaxis at birth. Similarly, mothers who took ART drugs less than 4 weeks were 1.92 times more likely to transmit HIV infection than those who were taking more than 4 weeks. The finding of this study result was agreed with studies done in French [61], Africa [62], and UK [63]. This is because early initiation of ART to the mother during pregnancy period plus prophylaxis of ART for HIV-exposed infants at birth decreases the viral load of the virus and reducing the chance of vertical HIV infections of newborns. 
Table 2 Univariate meta-regression analysis for vertical HIV infection in East Africa, 2019

\begin{tabular}{llll}
\hline & & Co-efficient & $\boldsymbol{p}$ value \\
\hline Year of study & & -0.225 & 0.696 \\
Sample size & 0.000 & 0.674 \\
Countries & Ethiopia & 5.9 & 1 \\
& Kenya & .232 & 0.8 \\
& Tanzania & .329 & 0.702 \\
& Uganda & 0.133 & 0.847 \\
& Eritrea & 1 & \\
Study design & Cross-sectional & -0.232 & 0.726 \\
& Cohort & 1 & \\
\hline
\end{tabular}

\section{Conclusions}

Generally, the pooled prevalence of vertical transmission of HIV is high in the study area compared to other studies. Thus, strengthening the prevention of mother to child transmission of HIV (PMTCT) program, promote exclusive breastfeeding, timely initiate ART prophylaxis for HIV exposed infants, and encourage hospital delivery, and timely initiation of ART drugs for mothers were recommended. It is the first meta-analysis carried out in East Africa. Only English articles were considered to carry out the analysis. Studies in this review were included only cross-sectional and cohort in nature, and therefore, the outcome variable might be affected by other confounding variables. The estimated report could be affected by the limited sample size.

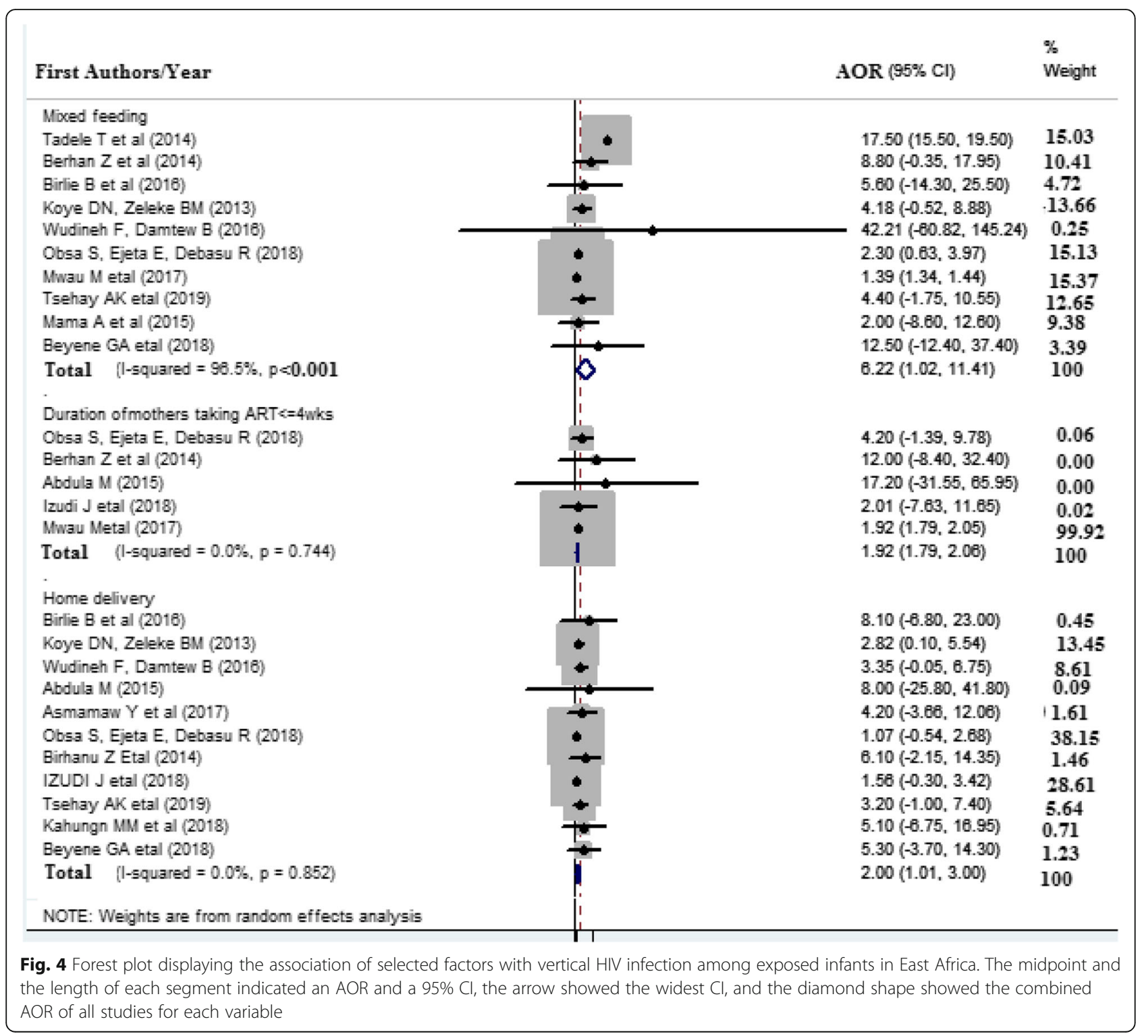




\begin{tabular}{|c|c|c|}
\hline & & $\%$ \\
\hline First Authors/year & AOR $(95 \% \mathrm{Cl})$ & Weight \\
\hline Tadele T et al (2014) & $0.19(-1.47,1.85)$ & 29.20 \\
\hline Berhan Z et al (2014) & $6.70(-32.78,46.18)$ & 0.06 \\
\hline Wudineh F, Damtew B (2016) & $5.83(-11.89,23.55)$ & 0.30 \\
\hline Asmamaw Y et al (2017) & $5.30(-42.34,52.94)$ & 0.04 \\
\hline Obsa S, Ejeta E, Debasu R (2018) & $18.10(-95.72,131.92)$ & 0.01 \\
\hline Mwau M etal (2017) & $2.76(1.80,3.72)$ & 69.72 \\
\hline Tsehay AK etal (2019) & $4.10(-17.56,25.76)$ & 0.20 \\
\hline Mama A et al (2015) & $1.40(-12.60,15.40)$ & 0.47 \\
\hline Overall $(1-$ squared $=3.2 \%, p=0.405$ ) & $2.02(1.05,2.98)$ & 100.00 \\
\hline NOTE: Weights are from random effects analysis & & \\
\hline
\end{tabular}

Fig. 5 Forest plot displaying the association of infants who were not received ART prophylaxis with vertical HIV infections among exposed infants in East Africa. The midpoint and the length of each segment indicated an AOR and a 95\% Cl, the arrow showed the widest $\mathrm{Cl}$, and the diamond shape showed the combined AOR of all studies for each variable

\section{Abbreviations}

ANC: Antenatal care; Cl: Confidence interval; EDHS: Ethiopian Demographic and Health Survey; HIV: Human immune deficiency virus; OR: Odds ratio; MTCT: Mother to child transmission; PMTCT: Prevention of mother to child transmission; WHO: World Health Organization

\section{Acknowledgements}

Not applicable.

\section{Authors' contributions}

AB: Conception of the research protocol, study design, literature review, data extraction, data analysis, interpretation, and drafting of the manuscript. AB: Data analysis and reviewing the manuscript. GA: reviewing the manuscript. $A B$ and TT: Data extraction and quality assessment. The authors have read and approved the manuscript.

\section{Funding}

No funding was obtained for this study.

\section{Availability of data and materials}

Data will be available upon request of the corresponding author.

\section{Ethics approval and consent to participate}

Not applicable.

\section{Consent for publication}

Not applicable

\section{Competing interests}

The authors have declared that they have no competing interests.

\section{Author details}

${ }^{1}$ Department of Pediatrics and Child Health Nursing, College of Medicine and Health Sciences, Bahir Dar University, Bahir Dar, Ethiopia. ${ }^{2}$ Department of Laboratory Science, Bahir Dar Health Science College, Bahir Dar, Ethiopia.
Received: 24 August 2020 Accepted: 30 September 2020

Published online: 20 October 2020

\section{References}

1. WHO. World Health Organization. HIV/AIDS factsheet. WHO. 2019.

2. WHO. PMTCT Strategic vision 2010 - 2015: preventing mother-to-child transmission of HIV to reach the UNGASS and Millenium Development Goals. Geneva: WHO; 2010

3. WHO. Antiretroviral drugs for treating pregnant women and preventing HIV infection in infants: recommendations for a public health approach. Geneva: WHO; 2010

4. Ethiopian Federal Ministry of Health. National Comprehensive PMTCT training participants manual. Adama: $\mathrm{FMOH} ; 2016$

5. Moges NA, Kassa GM, Boneya DJ. Rate of HIV transmission and associated factors among HIV-exposed infants in selected health facilities of East and West Gojjam Zones, Northwest Ethiopia; retrospective cohort study. BMC infectious diseases. 2017;17(1):475.

6. Obsa S, Dabsu R, Ejeta E. Rate of mother to child transmission of HIV and factors associated among HIV exposed infants in Oromia Regional State, Ethiopia: Retrospective study. Egyptian Pediatric Association Gazette. 2018; 66(3):61-5.

7. Birlie B, Diriba T, Sisay K, Gurmessa A, Seyoum D. Mother to child HIV transmission and its predictors among HIV-exposed infants: a retrospective follow-up study in Southwest Ethiopia. J AIDS Clin Res. 2016;7(605):2.

8. Derebe G, Biadgilign S, Trivelli M, Hundessa G, Robi ZD, Gebre-Mariam M, Makonnen M. Determinant and outcome of early diagnosis of HIV infection among HIV-exposed infants in southwest Ethiopia. BMC research notes. 2014 Dec;7(1):309.

9. Tadele T, Tamiso A, Tadele T. Incidences and predictors of HIV positivity among infants who born from HIV positive mother who have follow up at two hospitals of southern Ethiopia, 2014. Sci J Public Health. 2014;2(5):431-9.

10. Wudineh F, Damtew B. Mother-to-child transmission of HIV infection and its determinants among exposed infants on care and follow-up in Dire Dawa City, Eastern Ethiopia. AIDS research and treatment. 2016;2016.

11. Negash TG, Ehlers VJ. An assessment of the outcomes of prevention of mother-to-child transmission of HIV services in Addis Ababa. Ethiopia. Curationis. 2016;39(1):1-9. 
12. Sirengo M, Muthoni L, Kellogg TA, Kim AA, Katana A, Mwanyumba $S$, Kimanga DO, Maina WK, Muraguri N, Elly B, Rutherford GW. Mother-to-child transmission of HIV in Kenya: results from a nationally representative study. Journal of acquired immune deficiency syndromes (1999). 2014;661:S66.

13. Gamell A, Luwanda LB, Kalinjuma AV, Samson L, Ntamatungiro AJ, Weisser M, Gingo W, Tanner M, Hatz C, Letang E, Battegay M. Prevention of motherto-child transmission of HIV Option B+ cascade in rural Tanzania: the One Stop Clinic model. PloS one. 2017;12(7):e0181096.

14. Kahungu MM, Kiwanuka J, Kaharuza F, Wanyenze RK. Factors associated with HIV positive sero-status among exposed infants attending care at health facilities: a cross sectional study in rural Uganda. BMC public health. 2018;18(1):139

15. Mwau M, Bwana P, Kithinji L, Ogollah F, Ochieng S, Akinyi C, Adhiambo M, Ogumbo F, Sirengo M, Boeke C. Mother-to-child transmission of HIV in Kenya: a cross-sectional analysis of the national database over nine years. PloS one. 2017;12(8):e0183860.

16. Mwendo EM, Mtuy TB, Renju J, Rutherford GW, Nondi J, Sichalwe AW, Todd J. Effectiveness of prevention of mother-to-child HIV transmission programmes in K ilimanjaro region, northern T anzania. Tropical medicine \& international health. 2014 Mar;19(3):267-74.

17. Mirambo MM, Simon C, Kajura A, Kidenya B, Majigo M, Mshana SE. Reduction of HIV transmission rates from mother to child in the era of antiretroviral therapy in the Lake Victoria zone. Tanzania. Tanzania Journal of Health Research. 2015;17(3).

18. Izudi J, Apangu P, Bajunirwe F, Mulogo E, Batwala V. High baseline CD4 count and Exclusive breastfeeding are associated with lower rates of mother to child hiv transmission in northwestern uganda: a two-year retrospective cohort study. Advances in Public Health. 2018;2018.

19. Teclebirhan T, Berhane A, Mufunda J, Gebremichael A. Prevention of mother to child transmission of HIV/AIDS in Eritrea: the Eritrean experience. Journal of the Eritrean Medical Association. 2009;4(1):68-70.

20. Khobondo JO, Gicheru MM, Khamadi SA. Pediatric HIV-aids in Nairobi; prevalence, gender and implication for prevention of mother to child transmission. European Journal of Research in Medical Sciences. 2015;3(2).

21. Tsehay AK. Factors associated with HIV positive sero-status among exposed infants attending care at health facilities in Bahir Dar administration, Ethiopia: Evidence from Medical Records. Cogent Medicine. 2019 Jan 1(justaccepted): 1623754

22. Desta ML, Saravanan M, Hilekiros H, Kahsay AG, Mohamed NF, Gezahegn AA, Lopes BS. HIV prevalence and risk factors in infants born to HIV positive mothers, measured by dried blood spot real-time PCR assay in Tigray. Northern Ethiopia. BMC pediatrics. 2019 Dec 1;19(1):257.

23. Mirkuzie AH, Hinderaker SG, Mørkve O. Promising outcomes of a national programme for the prevention of mother-to-child HIV transmission in Addis Ababa: a retrospective study. BMC Health Serv Res. 2010;10(1):267.

24. Koye DN, Zeleke BM. Mother-to-child transmission of HIV and its predictors among HIV-exposed infants at a PMTCT clinic in northwest Ethiopia. BMC Public Health. 2013;13(1):398

25. MAMA A, TILAHUN Z, WORKINEH S. Assessment of effectiveness of prevention of mother to child transmission of human immunodeficiency virus in Asella hospital. Ethiopia. Eur J Clin Pharm. 2017;19(3):198-206.

26. Mirkuzie AH, Hinderaker SG, Sisay MM, Moland KM, Mørkve O. Current status of medication adherence and infant follow up in the prevention of mother to child HIV transmission programme in Addis Ababa: a cohort study. J Int AIDS Soc. 2011;14(1):50.

27. Berhan Z, Abebe F, Gedefaw M, Tesfa M, Assefa M, Tafere Y. Risk of HIV and associated factors among infants born to HIV positive women in Amhara region, Ethiopia: a facility based retrospective study. BMC research notes. $2014 \operatorname{Dec}_{i} 7(1): 876$

28. Amare H, Weldesenbet Z, Tsadik AG, Ayalew E, Aragaw R, Fatuma H, Desta $K$, Tsegaye A. Prevalence and risk factors of HIV infection among infants, born from HIV seropositive mothers, tested by DNA-PCR at yekatit 12 Hospital. Addis Ababa, Ethiopia.

29. Makau G, Okwara F, Oyore J. Determinants of early infant diagnosis and treatment of HIV among exposed infants in informal settlements in Nairobi. Kenya. East Cent Africa Med J. 2015;2:74-9.

30. Ashiono E, Achwoka D, Mutugi J, Rakwar J, Wafula A, Chabikuli ON. Vertical HIV transmission in perinatally-exposed infants in South-Rift region of Kenya: a retrospective cross sectional study. BMC public health. 2017;17(1):207.

31. Obai G, Mubeezi R, Makumbi F. Rate and associated factors of non-retention of mother-baby pairs in HIV care in the elimination of mother-to-child transmission programme, Gulu-Uganda: a cohort study. BMC health services research. 2017;17(1):48.

32. Gel G, Kitaka SB, Musiime V, Chollong H. Prevalence, clinical pattern and immediate outcomes of HIV-infected children admitted to Al Sabah Children's Hospital, South Sudan. South Sudan Medical Journal. 2019;12(3).

33. Buzdugan R, McCoy SI, Watadzaushe C, Dufour MS, Petersen M, Dirawo J, Mushavi A, Mujuru HA, Mahomva A, Musarandega R, Hakobyan A. Evaluating the impact of Zimbabwe's prevention of mother-to-child HIV transmission program: population-level estimates of HIV-free infant survival pre-Option A. PloS one. 2015 Aug 6;10(8):e0134571.

34. Ndaimani A, Chitsike I, Haruzivishe C, Stray-Pedersen B, Ndaimani H. Mother to child transmission of HIV and its option B+ cascade predictors: An ecological study. Annals of Tropical Medicine and Public Health. 2018 May 1;11(3):87.

35. van Lettow $M$, Landes $M$, van Oosterhout JJ, Schouten $E$, Phiri $H$, Nkhoma $E$, Kalua T, Gupta S, Wadonda N, Jahn A, Tippett-Barr B. Prevention of motherto-child transmission of HIV: a cross-sectional study in Malawi. Bulletin of the World Health Organization. 2018 Apr 1;96(4):256.

36. Mugwaneza P, Lyambabaje A, Umubyeyi A, Humuza J, Tsague L, Mwanyumba F, Mutabazi V, Nsanzimana S, Ribakare M, Irakoze A, Mutaganzwa E. Impact of maternal ART on mother-to-child transmission (MTCT) of HIV at six weeks postpartum in Rwanda. BMC Public Health. 2018 Dec 1;18(1):1248.

37. Yitayew YA, Bekele DM, Demissie BW, Menji ZA. Mother to child transmission of HIV and associated factors among HIV exposed infants at public health facilities, Dessie Town, Ethiopia. Hiv/aids (Auckland, NZ). 2019; 11:343.

38. Asmamaw $Y$, Mengistu D, Aragew Z. Mother to child HIV transmission and associated factors among HIV exposed infants at govermental health facilities, Dessie town, Ethiopia. Hiv/aids (Auckland, NZ) 2019 [research article]. In press 2017.

39. Beyene GA, Dadi LS, Mogas SB. Determinants of HIV infection among children born to mothers on prevention of mother to child transmission program of HIV in Addis Ababa, Ethiopia: a case control study. BMC infectious diseases. 2018 Dec;18(1):327.

40. Higgins JP, Thompson SG, Deeks JJ, Altman DG. Measuring inconsistency in meta-analyses. BMJ. 2003:327(7414):557.

41. Munn Z, Moola S, Lisy K, Riitano D. The Joanna Briggs institute reviewers' manual 2014. In: The systematic review of prevalence and incidence data. Adelaide: The Joanna Briggs Institute; 2014.

42. Egger M, Smith GD, Schneider M, Minder C. Bias in meta-analysis detected by a simple, graphical test. BMJ. 1997;315(7109):629-34.

43. Duval S, Tweedie R. A nonparametric "trim and fill" method of accounting for publication bias in meta-analysis. JASA. 2000;95(449):89-98.

44. Okoko NA, Owuor KO, Kulzer JL, Owino GO, Ogolla IA, Wandera RW, Bukusi EA, Cohen CR, Abuogi LL. Factors associated with mother to child transmission of HIV despite overall low transmission rates in HIVexposed infants in rural Kenya. International journal of STD \& AIDS. 2017;28(12):1215-23.

45. Williams AM, Chantry C, Geubbels EL, Ramaiya AK, Shemdoe Al, Tancredi DJ, Young SL. Breastfeeding and complementary feeding practices among HIVexposed infants in coastal Tanzania. Journal of Human Lactation. 2016;32(1): $112-22$.

46. Kassa GM. Mother-to-child transmission of HIV infection and its associated factors in Ethiopia: a systematic review and meta-analysis. BMC infectious diseases. 2018 Dec;18(1):216.

47. Makwaga O, Muigai A, Mokaya T, Mwau M. High prevalence of HIV infection among age sets of infants born to HIV infected mothers. THE KASH 7 ABSTRACT SUBMISSION. 2017 Jun 21.

48. Global health sector strategy on sexually transmitted infections, 2016-2021. Geneva: World Health Organization; 2016. Available from: http//www.who. int/reproductivehealth/publications/rits/ghss-sits/en/.

49. Zeng $H$, Chow EP, Zhao $Y$, Wang $Y$, Tang $M$, Li L, et al. Prevention of mother-to-child HIV transmission cascade in China: a systematic review and meta-analysis. Sex Transm Infect. 2016;92(2):116-23.

50. Ishikawa N, Newman L, Taylor M, Essajee S, Pendse R, Ghidinelli M. Elimination of mother-to-child transmission of HIV and syphilis in Cuba and Thailand. Bulletin of the World Health Organization. 2016;94(11):787

51. Sidibé M, Singh PK. Thailand eliminates mother-to-child transmission of HIV and syphilis. The Lancet. 2016;387(10037):2488-9. 
52. Goga A, Sherman G, Chirinda W, Ng'oma K, Bhardwaj S, Doherty T, Pillay Y, Barron P. Eliminating mother-to-child transmission of HIV in South Africa, 2002-2016: progress, challenges and the Last Mile Plan. South African health review. 2017:2017(1):137-46.

53. Gourlay A, Birdthistle I, Mburu G, lorpenda K, Wringe A. Barriers and facilitating factors to the uptake of antiretroviral drugs for prevention of mother-to-child transmission of HIV in sub-Saharan Africa: a systematic review. J Int AIDS Soc. 2013;16:18588.

54. Ogunbosi BO, Oladokun RE, Brown BJ, Osinusi KI. Prevalence and clinical pattern of paediatric HIV infection at the university college hospital, Ibadan, Nigeria: a prospective cross-sectional study. Ital J Pediatr. 2011;37(1):29.

55. World Health Organization. PMTCT strategic vision 2010-2015: preventing mother-to-child transmission of HIV to reach the UNGASS and Millennium Development Goals. 2010.

56. Hrdy DB. Cultural practices contributing to the transmission of human immunodeficiency virus in Africa. Rev Infect Dis. 1987;9(6):1109-19.

57. Milka WANJOHI, et al. Sociocultural factors influencing breastfeeding practices in two slums in Nairobi, Kenya. International breastfeeding journal. 2016;12(1):5

58. Ngwende S, Gombe NT, Midzi S, Tshimanga M, Shambira G, Chadambuka A. Factors associated with HIV infection among children born to mothers on the prevention of mother to child transmission programme at Chitungwiza hospital, Zimbabwe. 2008. BMC public health. 2013;13(1):1181.

59. Coovadia H, Rollins N, Bland R, Little K, Coutsoudis A, Bennish M, et al. Lancet: mother-to-child transmission of HIV-1 infection during exclusive breastfeeding in the first 6 months of life: an intervention cohort study. Breastfeeding Review. 2008;16(1):30-2.

60. Hurst SA, Appelgren KE, Kourtis AP. Prevention of mother-to-child transmission of human immunodeficiency virus type 1 (HIV): the role of neonatal and infant prophylaxis. Expert Rev Anti-Infect Ther. 2015;13(2): 169-81.

61. Warszawski J, Tubiana R, Le Chenadec J, Blanche S, Teglas JP, Dollfus C, Faye A, Burgard M, Rouzioux C, Mandelbrot L. ANRS French Perinatal Cohort. Mother-to-child HIV transmission despite antiretroviral therapy in the ANRS French Perinatal Cohort. Aids. 2008;22(2):289-99.

62. Kesho Bora Study Group. Triple antiretroviral compared with zidovudine and single-dose nevirapine prophylaxis during pregnancy and breastfeeding for prevention of mother-to-child transmission of HIV-1 (Kesho Bora study): a randomised controlled trial. The Lancet infectious diseases. 2011;11(3):171-80.

63. Townsend CL, Cortina-Borja M, Peckham CS, de Ruiter A, Lyall H, Tookey PA. Low rates of mother-to-child transmission of HIV following effective pregnancy interventions in the United Kingdom and Ireland, 2000-2006. Aids. 2008:22(8):973-81.

\section{Publisher's Note}

Springer Nature remains neutral with regard to jurisdictional claims in published maps and institutional affiliations.

Ready to submit your research? Choose BMC and benefit from:

- fast, convenient online submission

- thorough peer review by experienced researchers in your field

- rapid publication on acceptance

- support for research data, including large and complex data types

- gold Open Access which fosters wider collaboration and increased citations

- maximum visibility for your research: over $100 \mathrm{M}$ website views per year

At BMC, research is always in progress.

Learn more biomedcentral.com/submissions 